\title{
Effects of Acute and Chronic Cocaine Administration on EEG and Behaviour in Intact and Castrated Male and Intact and Ovariectomized Female Rats
}

\author{
E. L. J. M. VAN LUIJTELAAR, ${ }^{\star 1}$ R. DIRKSEN, $\dagger$ T. B. VREE† AND F. VAN HAAREN $\ddagger$ \\ Departments of ${ }^{\star} P$ sychology and †Anaesthesiology, University of Nijmegen, Nijmegan, The Netherlands \\ $\ddagger$ Department of Psychology, University of Florida, Gainesville Florida
}

[Received 28 April 1995; Revised 23 November 1995; Accepted 30 November 1995]

\begin{abstract}
Intact and gonadectomized male and female WAG/ Rij rats were used to study the effects of gender and gonadal hormones on the development of sensitization and tolerance to cocaine-induced changes in EEG and behaviour. The four groups of WAG/Rij rats differed in the number of spontaneously occurring spike-wave discharges: ovariectomy decreased and castration increased the number of spike-wave discharges. This confirms that testosterone has antiabsence effects and that female gonadal hormones may promote the occurrence of spikewave discharges. Cocaine [10 and $20 \mathrm{mg} / \mathrm{kg}$, intraperitoneally (IP)] was administered before and after chronic cocaine administration ( 9 days, one daily injection with $10 \mathrm{mg} / \mathrm{kg}$ ) and EEG and behaviour were monitored. Cocaine strongly suppressed the occurrence of spike-wave discharges before and after chronic administration in all four groups, although the decrease was less in the intact males. Sensitization or tolerance induced by cocaine on EEG could not be established. Acute cocaine administration eliminated explorative, automatic, and passive behaviour, whereas various stereotypical activities such as uncoordinated head and body movements and head swaying emerged. Differences between groups were observed as intact males were less likely than subjects in the three other groups to engage in intense stereotyped behaviour. These data suggest that testosterone inhibits EEG and behavioural effects of acute cocaine administration. All four groups displayed less head swaying and more uncoordinated head and body movements after chronic cocaine administration, suggesting that behavioural sensitization had occurred. Differences between the four groups had faded away. Although pharmacokinetic differences in levels of cocaine and benzoylecgonine between the four groups were found, they could not easily be related to the behavioural differences between groups.
\end{abstract}

KEY WORDS: Cocaine, WAG/Rij strain, Rats, Spike-wave discharges, Chronic treatment, Stereotype behaviour, Gender, Sex hormones.

\section{INTRODUCTION}

Acute administration of cocaine produces an increase in locomotor activity and stereotyped behavior and has stimulant or depressant effects on the CNS [e.g., (49)]. Chronic cocaine ad- ministration may lead to tolerance or sensitization for its behavioural and central effects [16]. Cocaine's stimulant or depressant effect may be evident from its pro- or antiepileptic actions. Stripling and Russell [37] demonstrated an antiepileptic action in rats, and Karler et al. [16] found an initial increase on electroshock convulsion threshold. Others have demonstrated a proconvulsant effect of cocaine (e.g., flurothyl-induced convulsions in mice were aggravated) [14], and some authors have suggested that as a consequence of repeated administration, an increased sensitivity for cocaine-induced seizures may develop [23]. It is interesting to note that in the vast majority of these experimental models only male subjects were used and that information concerning the effects of cocaine on nonconvulsive epilepsy is completely lacking.

It has previously been shown that rats of the WAG/Rij strain are genetically predisposed to show spike-wave discharges in their electroencephalogram (EEG). Spike-wave discharges occur spontaneously several hundred times per day [41]. These seizures can be blocked by two classes of antiepileptic drugs: the broad-spectrum antiepileptic drugs such as benzodiazepines, valproate, and loreclezole; and typical antiabsence drugs such as trimethadione and ethosuximide $[1,28]$. These data support the validity of the WAG/Rij rat as a model for human absence epilepsy [5], especially as behavioural experiments have established a decrease in performance in a time-estimation task in trials with spike-wave activity in both humans and rat $[43,44]$.

The present experiment was designed to investigate the effects of acute and chronic cocaine administration on behaviour and on a nonconvulsive type of epilepsy in intact and gonadectomized male and female rats. These four groups of rats were included because other experiments have shown that gonadal secretions may be important determinants of the behavioural effects of acute and chronic cocaine administration, for example [39,40]. In addition, plasma concentrations of cocaine and its major metabolite benzoylecgonine were determined in anesthesized rats after chronic administration to gain some knowledge about possible pharmacokinetic differences between intact and gonadectomized male and female rats.

\footnotetext{
' Requests for reprints should be addressed to G. van Luijtelaar, NICI, Department of Psychology, University of Nijmegen, PO Box 9104,6500 HE Nijmegen, The Netherlands. E-mail address: Luijtelaar@nici.Kun.nl
} 


\section{METHODS}

\section{Subjects}

A total of 48 Wistar Albino Glaxo (WAG/Rij) rats served as subjects: 24 males and 24 females. They were housed in samesex pairs under a reversed 12 L:12 D cycle (lights on at 2000 h). When they were 3 mo old, 12 males and 12 females were castrated and ovariectomized, respectively, under $45-60 \mathrm{mg} / \mathrm{kg}$ Nembutal anaesthesia, whereas the other 24 subjects, 12 in each group, were sham-operated. At 3 mo later, when the rats were at 6 mo of age, all rats were equipped again under the same dose of Nembutal with a tripolar EEG electrode (MS 333/2-A; Plastic One Roanoke, VA, USA). The first active electrode was placed at the frontal region: the second one was located occipitally. The reference electrode was above the cerebellum $[41]$.

\section{EEG Recording}

The EEG signal was amplified and filtered by an ElemaSchönander polygraph; only frequencies between 1 and $70 \mathrm{~Hz}$ were allowed to pass. The EEG was subsequently stored in digitized form on magneto-optical disk. The EEGs were visually scored off-line on number and duration of spontaneously occurring spike-wave discharges $[41]$.

\section{Behavioural Recordings}

The following behavioural categories were observed: exploratory behaviour (walking, rearing, sniffing, and digging), automatic behaviour (grooming, eating, and drinking), and passive behaviour ( sitting, lying down, and standing still) [8]. After the first cocaine injections it was obvious that these categories were not sufficient to describe the behaviour of the rats adequately, and three other behavioural categories were added: standing or sitting still with head movements (swaying), standing still with uncoordinated head movements, and uncoordinated ambulation. Therefore, the cocaine behavioural data are based on fewer subjects than the EEG data. Behaviour was observed through a window from an adjacent room by two experienced observers who were blinded as to the treatment groups. The data were recorded and analysed with a PC-based registration software package [27].

\section{High-Performance Liquid Chromatography ( $H P L C$ )}

Concentrations of cocaine and benzoylecgonine were determined by HPLC as described by Lampert and Stewart [20], Lau et al. [21], and Tebbett and McCartney [38]. Briefly, the column was C18 spherisorb 5 ODS $250 * 4.6 \mathrm{~mm}$. The mobile phase consisted of $50 \%$ acetronitrile and $50 \%$ orthophosphoric acid ( $0.6 \mathrm{~g} / 1$ plus $0.4 \mathrm{~g}$ tetramethylammonium-chloride) (v/v). Mobile flow was $1.5 \mathrm{ml} / \mathrm{min}$, retention time of benzoylecgonine was $2 \mathrm{~min}$, and that of cocaine was $6 \mathrm{~min}$. Plasma was extracted with baker-bond octadecyl $\mathrm{C} 18$ cartridges. Intraday and interday variations of both cocaine and benzoylecgonine were $<10 \%$. Recovery of plasma extraction was $87 \%$ for cocaine and $43 \%$ for benzoylecgonine.

\section{Procedure}

The animals were allowed to recover from EEG surgery for at least a week before they were adapted to the recording leads for a minimum of $16 \mathrm{~h}$. The baseline EEG was recorded for $1 \mathrm{~h}$, always during the same hour of the dark period. The spontaneous behaviour of the rats was observed and quantified for $30 \mathrm{~min}$ during the baseline period. Intact females served only when not in oestrus. If lordosis occurred in the presence of an adult male rat, the animal was excluded from the experiment. Male and ovariectomized rats were placed with a nonreceptive female or normal male, respectively, for control purposes only. Because cocaine disrupts the oestrus cyclicity, it was not thought to be meaningful to determine behavioural oestrus before the second cocaine tests.

\section{Acute Effects of 10 and $20 \mathrm{mg} / \mathrm{kg}$ Cocaine}

After the behavioural test, all subjects were injected intraperitoneally (IP) with saline in a volume of $1 \mathrm{ml}$. The EEG was then recorded for $1 \mathrm{~h}$, followed by an IP injection of $10 \mathrm{mg} / \mathrm{kg}$ cocaine hydrochloride (Sigma Chemical Corp., St. Louis, MO) and $1 \mathrm{~h}$ of EEG recording, followed by the administration of 20 $\mathrm{mg} / \mathrm{kg}$ cocaine hydrochloride, IP, followed by the final hour of EEG recording. The spontaneous behaviour of the rats was observed and quantified for $30 \mathrm{~min}$ after saline injection, and after 10 and $20 \mathrm{mg} / \mathrm{kg}$ cocaine as well. Observation always started 5 min after injection.

\section{Effects of 10 and $20 \mathrm{mg} / \mathrm{kg}$ Cocaine After Chronic Cocaine Administration}

All subjects were subsequently treated with cocaine hydrochloride $(10 \mathrm{mg} / \mathrm{kg}$ ) for 9 consecutive days. On day 10 the EEG was recorded for 3 successive $h$ at the same time of day as previously, the $1 \mathrm{st} h$ after administration of saline, and the 2 nd $h$ after 10 and the $3 \mathrm{rd} \mathrm{h}$ after $20 \mathrm{mg} / \mathrm{kg}$ cocaine hydrochloride, IP. Behavioural recordings were made as described for after acute administration. The next day, the animals were tested again after 10 and $20 \mathrm{mg} / \mathrm{kg}$ cocaine hydrochloride, IP, in a pain sensitivity test [12], during which blood samples were collected under urethane anaesthesia from the internal jugular vein 5, 30, and $55 \mathrm{~min}$ after the injection of 10 and $20 \mathrm{mg} / \mathrm{kg}$ IP cocaine hydrochloride, respectively.

\section{Statistical Analysis}

Overall effects with respect to number and duration of spike wave discharges, behaviour, and plasma levels of cocaine and benzoylecgonine were analysed by means of a two-factor (gender and hormonal condition) analysis of variance (ANOVA) when necessary, followed by posthoc tests according to Duncan. If dose-effects had to be established, a three-factor ANOVA was done. Within-group effects for establishing tolerance or sensitization were analysed with paired $t$-tests. The differential development of tolerance or sensitization for the four groups was evaluated with a two-factor (gender and hormonal condition) ANOVA on the difference scores (data of the first - data of the second administration of the same dose of cocaine; saline - cocaine $10 \mathrm{mg} / \mathrm{kg}$; or saline $-20 \mathrm{mg} / \mathrm{kg}$ ).

\section{RESULTS}

\section{EEGs During Baseline}

Figure 1 shows the number of spike-wave discharges per hour for the four groups during the baseline period. Significant differences were found for the number of spike-wave discharges $(F=$ 4.23, df $1,36, p<0.05$ ), as males had more spike-wave discharges than females. A significant interaction between gender and hormonal condition was found $(F=4.49, d f 1,36, p<0.05)$. The posthoc test revealed that the castrated males had more spike-wave discharges than the ovariectomized females.

The mean duration of spike-wave discharges did not differ among the four groups. A significant gender difference was observed for the total duration of epileptic activity $(F=10.4, d f$ 

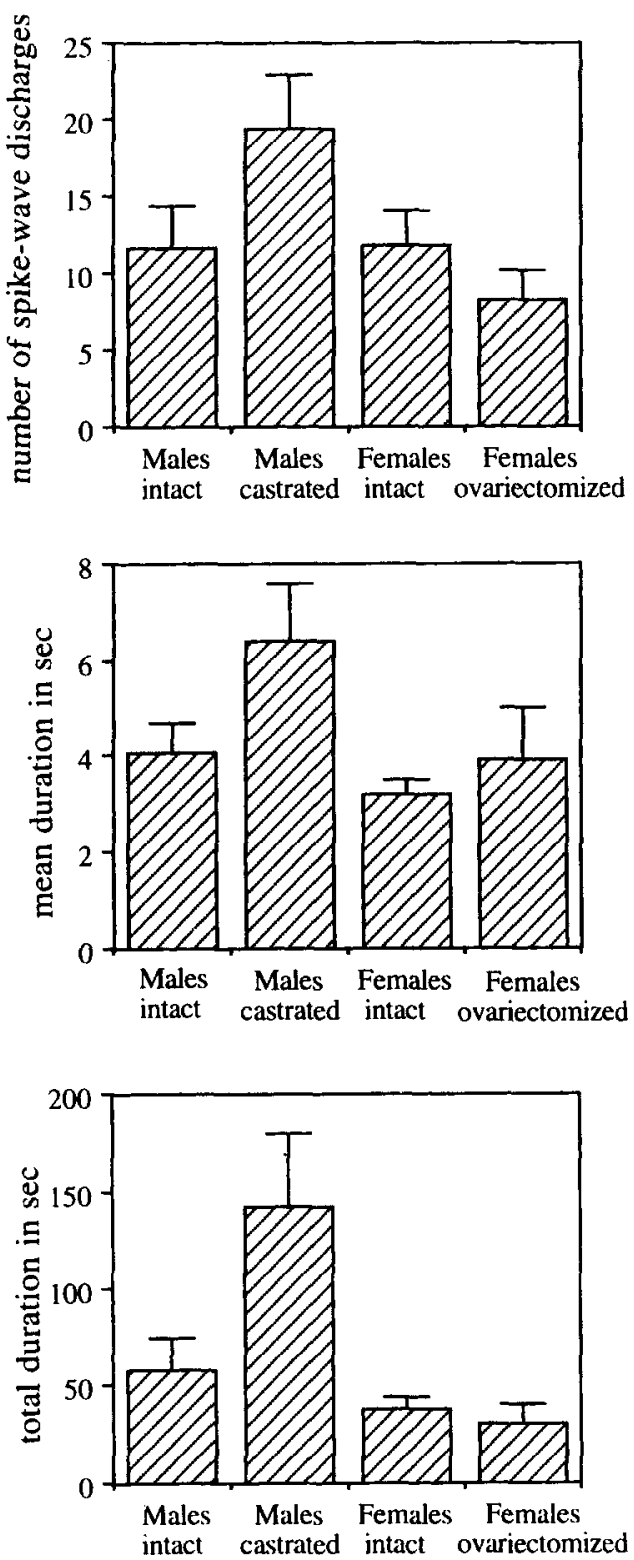

FIG. 1. The mean and SEM of the number (top), average duration (middle), and total duration (bottom) of spike-wave discharges of intact and castrated male and intact and ovariectomized female WAG/Rij rats observed during baseline conditions.

$1,36, p<0.01)$. Males scored higher than females, and there was also a significant interaction between gender and hormonal condition $(F=4.9, d f 1,36, p<0.05)$. The posthoc test revealed that the total duration of epileptic activity was higher for the castrated males than for any other group.

\section{EEG Effects After Acute Cocaine Administration}

Cocaine administration did not induce convulsions, but both doses of the drug strongly reduced the number of spike-wave discharges. The data are depicted in Fig. 2.

The within-group comparisons between the saline and the two cocaine groups and the ANOVA of the difference scores (saline $10 \mathrm{mg} / \mathrm{kg}$; and saline $20 \mathrm{mg} / \mathrm{kg}$ cocaine), which yielded interactions between gender and hormonal condition $(F=8.23, d f$
$1,36, p<0.01 ; F=5.10, d f 1,36, p<0.05$ ), and the subsequent posthoc tests confirmed that both doses of cocaine reduced the number of spike-wave discharges. The change from control to the low dose of cocaine was less $(p$ 's $<0.05$ ) for the intact males and ovariectomized females compared with that of the castrated males. There were no significant differences among the four groups with respect to the number of spike-wave discharges after the first injection of 10 or after $20 \mathrm{mg} / \mathrm{kg}$ cocaine. Because few animals had spike-wave discharges after cocaine, it was not meaningful to analyse statistically the mean and total duration of spike-wave discharges, although the same tendencies, a decrease for the number and total duration of spike-wave discharges was generally found.

\section{EEG Effects of Cocaine After Chronic Administration}

The number of spike-wave discharges was strongly reduced after the administration of 10 and $20 \mathrm{mg} / \mathrm{kg}$ cocaine. There were no differences between the effects of the two doses of cocaine: They equally suppressed the number of spike-wave discharges. The within-group comparison between the saline and the $10-\mathrm{mg} /$ $\mathrm{kg}$ cocaine group, the ANOVA of this difference score, which yielded an interaction between gender and hormonal condition ( $F=5.80$, df $3,34, p<0.05)$, and the posthoc tests again showed a smaller decrease for the intact males and ovariectomized females compared with the castrated males. The female groups did not differ in that respect. The differences between the four groups in the control and the large-dose cocaine in the reduction of spike-wave discharges had disappeared. No significant differences among the four groups in the number of spike-wave discharges were detected after 10 or after $20 \mathrm{mg} / \mathrm{kg}$ cocaine. There was no evidence of tolerance or sensitivity with respect to the number of spike-wave discharges as appeared from the $t$-tests for paired observations.

\section{Behaviour During Baseline}

There were no significant differences between intact and gonadectomized male and female WAG/Rij rats during the baseline period. The ANOVA showed a significant interaction of gender

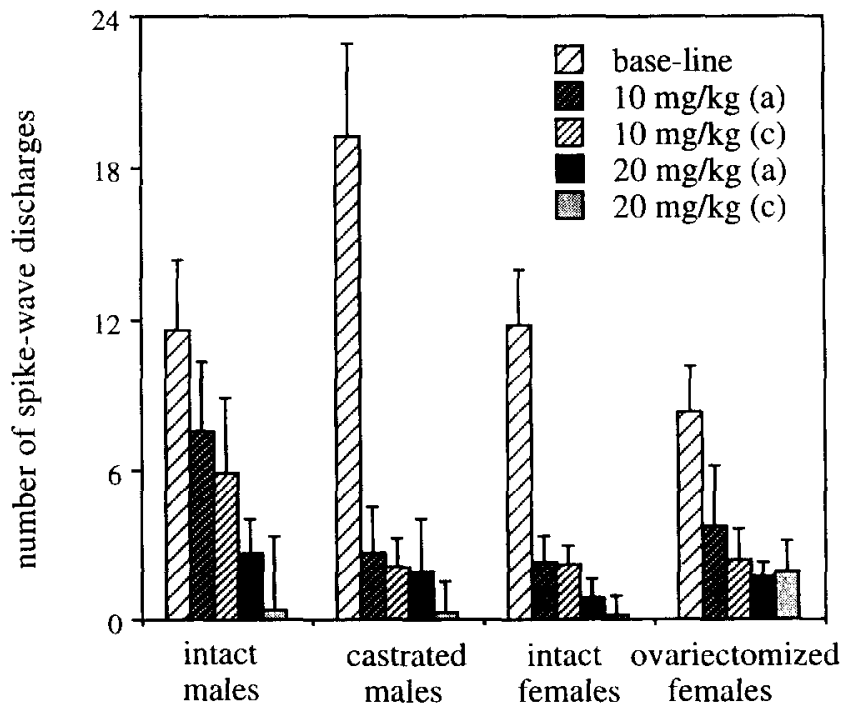

FIG. 2. The mean and SEM of the number of spike-wave discharges of the base-line period and after 10 and $20 \mathrm{mg} / \mathrm{kg}$ cocaine, IP, before (a) and after (c) chronic cocaine ( 9 days) administration (see procedure). 
and hormonal condition after saline administration for passive behaviour $(F=5.09$, df $1,22, p<0.05)$ : Intact females were more active than intact males. The behavioural data observed during the $1-\mathrm{h}$ precocaine baseline period are presented in Fig. 3.

\section{Acute Effects of Cocaine on Behaviour}

Figure 3 shows the effects of acute cocaine on the time that subjects were engaged in the different behavioural activities. In general, cocaine reduced automatic and passive behavior and in creased head swaying, immobility with chaotic head movements, and uncoordinated ambulation. After $10 \mathrm{mg} / \mathrm{kg}$ cocaine, an interaction between gender and hormonal condition was found for head swaying ( $F=5.89, d f 1,24, p<0.05)$ : Intact males showed more head swaying than subjects in the other groups. After 20 $\mathrm{mg} / \mathrm{kg}$ cocaine, rather strong and highly significant effects were found for head swaying: Gender $(F=14.25$, $d f 1.24, p<$ 0.001 ), hormonal condition $(F=22.87$, df 1,24, $p<0.0001$ ), and their interaction $(F=11.74, d f 1,24, p<0.001)$ were all significant. The intact males, who differed from the three other groups, showed this behavior almost $74 \%$ of the time, castrated males $7 \%$, intact females $23 \%$, and ovariectomized females $9 \%$. Finally, gender differences were found for uncoordinated head movements $(F=4.62, d f 1,24, p<0.05)$ : Females showed more chaotic behaviour than males.

\section{Behavioural Effects of Cocaine After Chronic Administration}

No differences were found among the four groups after saline administration. Qualitatively, the effects of cocaine after chronic administration seemed to be even more intense than after the acute injection. A dose of $10 \mathrm{mg} / \mathrm{kg}$ cocaine reduced passive and automatic behavior and increased uncoordinated head movements and uncoordinated ambulation, whereas $20 \mathrm{mg} / \mathrm{kg}$ cocaine abolished almost all explorative, automatic, and passive behaviour and further increased stereotype behaviour. A significant gender $(F=4.54, d f 1,24, p<0.05)$, hormonal condition $(F=$ 7.74. $d f 1,24, p<0.01)$ and a significant interaction effect $(F=$ 4.67. df $1.24, p<0.05$ ) was found after $10 \mathrm{mg} / \mathrm{kg}$ cocaine: Intact male WAG/Rij rats were more passive than subjects in the three other groups. Females also showed more uncoordinated head movements than males ( $F=7.49$, df 1,24, $p<0.05$ ), but the lighter form of stereotype behaviour, head swaying, ( $F=8.44$, df $1.24, p<0.01)$ occurred more often in males. There were no differences between the groups after $20 \mathrm{mg} / \mathrm{kg}$ of cocaine.

\section{Comparison Between Acute and Chronic Cocaine Effects on Behaviour}

As can be seen in Fig. 3, behaviour after saline administration was not substantially different before and following chronic cocaine administration; only exploratory behaviour was increased after chronic administration in castrated male rats. However. large differences before and after chronic treatment were observed mainly in intact male rats after both 10 and $20 \mathrm{mg} / \mathrm{kg}$ cocaine, as became evident from the within-group comparisons and from the ANOVA of the difference score (days 1-9). After $10 \mathrm{mg} / \mathrm{kg}$ cocaine following chronic administration, head swaying was decreased $(p<0.01)$ and chaotic head movements and uncoordinated ambulation were increased ( $p$ 's $<0.05$ ). Passive behaviour decreased $(p<0.05$ ) only in both female groups. Differences before and after chronic treatment were also present for intact males after $20 \mathrm{mg} / \mathrm{kg}$ cocaine following chronic co-
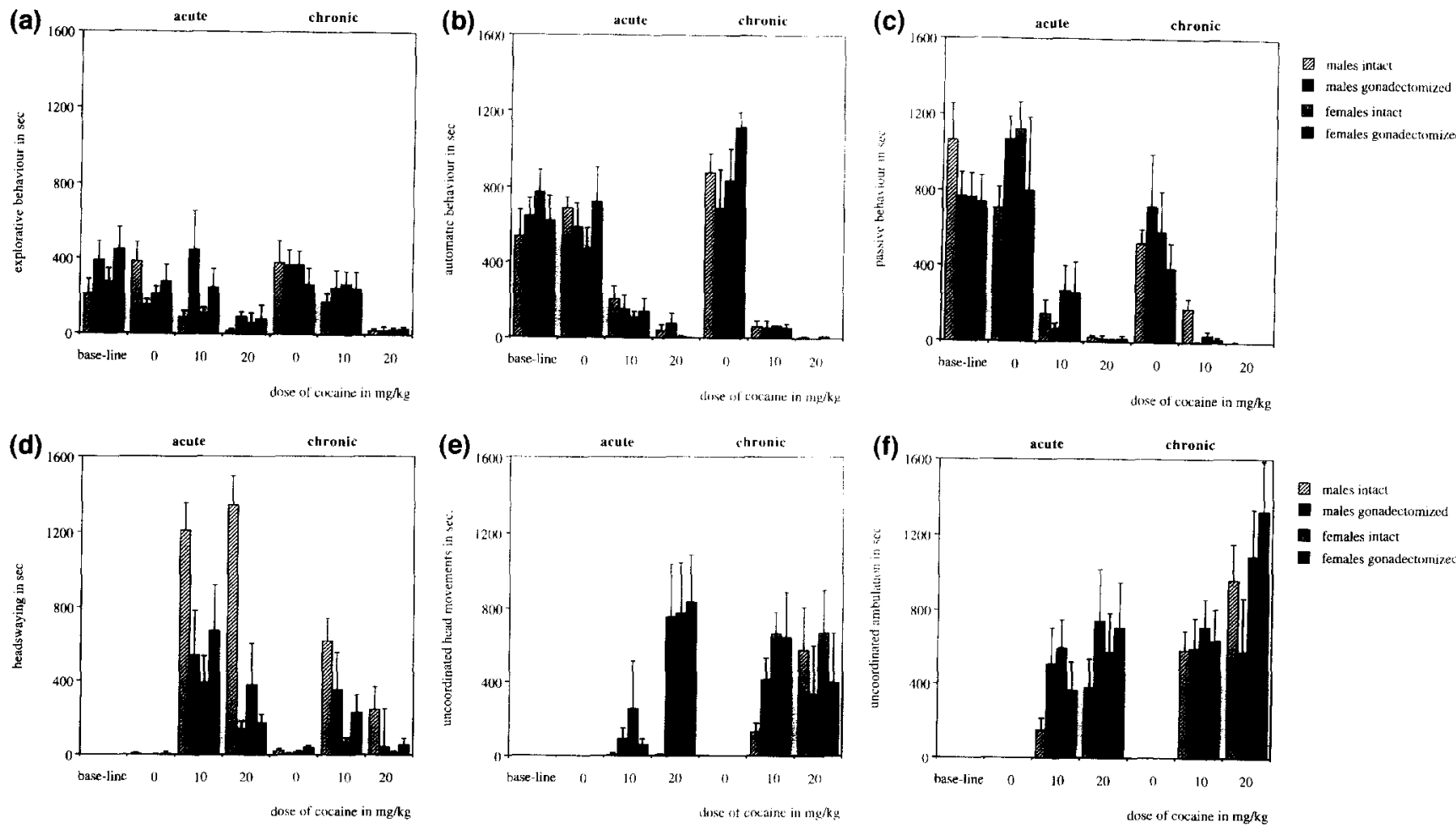

FIG. 3. The mean and SEM of the duration of six behavioural categories as observed in the home cage during the baseline period, and after saline and 10 and $20 \mathrm{mg} / \mathrm{kg}$ cocaine before (acute) and after (chronic) intermittent (9 days, one injection of $10 \mathrm{mg} / \mathrm{kg}$ daily) injections of cocaine. (a) explorative, (b) automatic, (c) passive, (d) head swaying, (e) uncoordinated head movements, and (f) uncoordinated ambulation are depicted. 
caine administration. Head swaying decreased $(p<0.0001)$, and chaotic head movements and uncoordinated ambulation ( $p$ 's $<$ $0.05)$ were increased. The ANOVA confirmed the differential response among the four groups after chronic treatment, and a gender $(F=5.20, d f 1,22, p<0.01)$, hormonal condition $(F=$ $15.88, d f 1,22, p<0.001)$ and an interaction effect $(F=5.98$, df $1,22, p<0.05$ ) were observed for head swaying: Intact males showed a larger decrease following chronic cocaine administration than the three other groups. The ANOVA for chaotic head movements showed a gender difference ( $F=4.66$, df $1,22, p<$ 0.05: an increase for males and a decrease for females) and a hormonal effect $(F=5.86, d f 1,22, p<0.05)$. This effects was caused by an increase in chaotic head movements for the intact males and a decrease for the other three groups.

\section{Cocaine Levels}

Plasma concentrations of cocaine and benzoylecgonine as measured 10,30 , and $55 \mathrm{~min}$ after 10 and $20 \mathrm{mg} / \mathrm{kg}$ cocaine administration and areas under the curve (AUC) for the four groups are presented in Table 1 . After $10 \mathrm{mg} / \mathrm{kg}$ cocaine, the concentration of cocaine decreased over time $(p<0.05)$ for males only as appeared from the $t$-test for paired observations (the difference between the score at 10 - the score at $55 \mathrm{~min}$ after administration). The concentrations of benzoylecgonine tended to increase, although this difference was only significant $(p<0.05)$ for intact males. After $20 \mathrm{mg} / \mathrm{kg}$, a steady state was found in the plasma concentrations of cocaine except for the intact males, which showed a decrease. The concentration of benzoylecgonine increased ( $p$ 's $<0.05$ ) for all four groups.

Higher concentrations of cocaine $(F=103.98$, df 1,51, $p<$ $0.0001)$ and benzoylecgonine $(F=81.46, d f 1,52, p<0.001)$ were found after $20 \mathrm{mg} / \mathrm{kg}$ than after $10 \mathrm{mg} / \mathrm{kg}$ cocaine. Differences among the four groups after the injection of $10 \mathrm{mg} / \mathrm{kg}$ were found for the AUC $(F=6.77, d f 1,25, p<0.05)$ : The males had a higher cocaine concentration than the females. Differences among the four groups were also found for the AUC ( $F=5.26$, $d f 1,26, p<0.05$ ) and for the cocaine concentration 55 min after the injection of $20 \mathrm{mg} / \mathrm{kg}(F=9.56, d f 1,28, p<0.01)$, the gonadectomized animals had a larger area and a corresponding higher concentration than the intact groups. This latter effect was also evident from the decrease over time; after $20 \mathrm{mg} / \mathrm{kg}$ the gonadectomized animals eliminated cocaine more slowly than did the intact animals $(F=4.36, d f 1,27, p<0.05)$. Differences among the four groups were not detected for benzoylecgonine.

\section{DISCUSSION}

The results of the present experiment are important for a number of reasons, because gender and hormonal effects were found on epilepsy parameters and cocaine yielded differential effects in the four groups of rats. First, gender and hormonal effects on spike-wave discharges will be discussed, followed by the effects of cocaine after acute and chronic administration on behaviour.

Intact male and female rats of the WAG/Rij strain exhibited spike-wave discharges, as described earlier [e.g., (5,41)]. Gender differences with respect to number and total duration of spike-wave discharges were observed: Males had more and longer spike-wave discharges than females. This difference between the sexes was mainly due to the contribution of the castrated males, who showed the largest number of spike-wave discharges. There were no differences between intact males and females. This latter finding is in agreement with an earlier study in which no differences between intact males and females were found [7], and with the finding that the epileptic gene thought to be responsible for the presence of spike-wave discharges in this particular strain is not coupled to the sex chromosome and therefore autosomal dominant [28].

Sex differences have been observed in other epilepsy models. For instance, Wilson [47] reported that males are more susceptible to bicuculline-induced seizures than females. In agreement with these observations, Kokka et al. [17] provided evidence to

TABLE 1

MEAN AND SEM OF PLASMA CONCENTRATION $(\mu \mathrm{g} / \mathrm{ml}$ ) OBSERVED 5,30 , AND $55 \mathrm{~min}$ AND AREA UNDER THE CURVE (AUC $\mu / \mathrm{ml} \cdot \mathrm{h})$ OF COCAINE AND BENZOYLECGONINE FOLLOWING 10 AND $20 \mathrm{mg} / \mathrm{kg}$ OF IP COCAINE

\begin{tabular}{|c|c|c|c|c|c|}
\hline \multirow[b]{2}{*}{ Group } & \multirow[b]{2}{*}{ Dose of Cocaine } & \multicolumn{3}{|c|}{ Cocaine } & \multirow[b]{2}{*}{ AUC } \\
\hline & & $5 \mathrm{~min}$ & $30 \mathrm{~min}$ & $55 \mathrm{~min}$ & \\
\hline \multirow[t]{2}{*}{ Intact males $(n=7-8)$} & 10 & $0.42 \pm 0.06$ & $0.36 \pm 0.06$ & $0.25 \pm 0.04$ & $0.31 \pm 0.03$ \\
\hline & 20 & $1.53 \pm 0.27$ & $1.27 \pm 0.27$ & $0.89 \pm 0.13$ & $1.13 \pm 0.20$ \\
\hline \multirow[t]{2}{*}{ Castrated males $(n=7-9)$} & 10 & $0.48 \pm 0.13$ & $0.34 \pm 0.04$ & $0.26 \pm 0.05$ & $0.31 \pm 0.06$ \\
\hline & 20 & $1.80 \pm 0.27$ & $1.78 \pm 0.23$ & $2.01 \pm 0.31$ & $1.77 \pm 0.26$ \\
\hline \multirow[t]{2}{*}{ Intact females $(n=7-9)$} & 10 & $0.32 \pm 0.04$ & $0.29 \pm 0.03$ & $0.23 \pm 0.02$ & $0.24 \pm 0.02$ \\
\hline & 20 & $1.17 \pm 0.28$ & $1.08 \pm 0.23$ & $1.13 \pm 0.31$ & $1.05 \pm 0.24$ \\
\hline \multirow{3}{*}{ Ovariectomized females $(n=6-7)$} & 10 & $0.31 \pm 0.10$ & $0.23 \pm 0.04$ & $0.17 \pm 0.02$ & $0.20 \pm 0.04$ \\
\hline & 20 & $1.48 \pm 0.17$ & $1.42 \pm 0.14$ & $1.61 \pm 0.25$ & $1.35 \pm 0.12$ \\
\hline & \multicolumn{5}{|c|}{ Benzoylecgonine } \\
\hline \multirow[t]{2}{*}{ Intact males $(n=8-9)$} & 10 & $0.33 \pm 0.08$ & $0.44 \pm 0.08$ & $0.50 \pm 0.05$ & $0.37 \pm 0.05$ \\
\hline & 20 & $1.70 \pm 0.22$ & $2.45 \pm 0.38$ & $3.14 \pm 0.52$ & $2.31 \pm 0.31$ \\
\hline \multirow[t]{2}{*}{ Castrated males $(n=7-9)$} & 10 & $0.45 \pm 0.11$ & $0.57 \pm 0.12$ & $0.99 \pm 0.43$ & $0.58 \pm 0.07$ \\
\hline & 20 & $2.16 \pm 0.31$ & $3.88 \pm 1.0$ & $4.78 \pm 1.2$ & $3.43 \pm 0.89$ \\
\hline \multirow[t]{2}{*}{ Intact females $(n=7-9)$} & 10 & $0.32 \pm 0.05$ & $0.41 \pm 0.06$ & $0.78 \pm 0.24$ & $0.39 \pm 0.05$ \\
\hline & 20 & $1.70 \pm 0.36$ & $2.52 \pm 0.58$ & $2.65 \pm 0.65$ & $2.14 \pm 0.47$ \\
\hline \multirow[t]{2}{*}{ Ovariectomized females $(n=7)$} & 10 & $0.35 \pm 0.06$ & $0.40 \pm 0.07$ & $0.54 \pm 0.09$ & $0.38 \pm 0.05$ \\
\hline & 20 & $1.94 \pm 0.24$ & $2.58 \pm 0.40$ & $3.65 \pm 0.46$ & $2.39 \pm 0.27$ \\
\hline
\end{tabular}


show that males have a lower threshold than females for seizures induced by pentylenetetrazol. Others, however, have shown that females are more susceptible than males for audiogenic convulsions [25]. These three studies illustrate that the direction of sex differences in susceptibility or sensitivity for convulsive epilepsy in intact animals largely depends on the type and nature of the epilepsy model. In any case, gender effects appear to be present in models in which epilepsy is chemically or otherwise induced, and are absent in a genetic model for absence epilepsy.

The significant interaction between gender and gonadectomy suggests that spike-wave activity may be functionally related to testosterone activity, and the difference between intact and gonadectomized animals suggests that testosterone has antiabsence effects. Testosterone does nor prevent tonic-clonic seizures in dogs [9], but it diminishes audiogenic seizures in rats [46]. Thus, it seems that both audiogenic seizures and spike-wave discharges are inhibited by testosterone and that testosterone has, albeit weak, both anticonvulsant and antiabsence properties [10]

Ovariectomy reduced spike-wave discharges in female rats, suggesting that oestradiol facilitates spike-wave discharges in intact animals. This confirms the general view that estrogenes are proconvulsant as hippocampal and amygdaloid seizure thresholds are decreased [48] and hippocampal discharge rate is enhanced [31]. Also, Newmark and Penry [26] concluded that there is an increased seizure sensitivity to estrogenes in a wide variety of models. In woman, a higher seizure frequency has been linked to peak oestrogen levels during the menstrual cycle [24] Bäckström [2] observed in patients with mixed seizure types that the generalised seizures, but not the partial ones, appeared to be cyclic and were associated with changes in oestrogen levels in the ovulatory patients. Puberty in man is also the period in which absences may change into more serious types of generalised epilepsy, and female sex hormones might be involved in this effect. We suggest that the slightly less favourable prognosis for girls than for boys $[11,34]$ may be a result of the proconvulsant effects of female steroid hormones and the antiepileptic activity of testosterone.

It appears to be without doubt than male and female sex hormones have an effect on the CNS and that steroid hormones also affect thalamic areas [22]. Spike-wave discharges are thought to result from the interplay of an thalamic oscillator and a reciprocal connection of thalamic and cortical neuronal populations $[3,36]$. This opens the possibility that sex hormones may have a specific action on thalamic neurotransmission and that they may modulate the amount of spike-wave activity [22]. Future experiments may show that intrathalamic injections of testosterone inhibits and oestradiol facilitates the number and duration of spike-wave discharges.

Administration of 10 and $20 \mathrm{mg} / \mathrm{kg}$ cocaine almost completely eliminated spike-wave discharges, and there were no gender differences after the injection. However, the diminishment of the number of spike-wave discharges as appeared from the comparison between saline and cocaine was significantly less in intact males compared with the three other conditions, suggesting that testosterone reduced the effects of the lower dose of cocaine. There are two not necessarily exclusive ways to explain the suppressing effects of cocaine on the number of spike-wave discharges. The first line of reasoning is based on the well-known relationship between vigilance states, locomotor activity, and spike-wave discharges. Spike-wave discharges predominantly occur during immobility when vigilance levels are relatively low $[5,6,13]$. High levels of locomotor activity including stereotypical behavior, as observed in the present experiment after cocaine administration suppressed spike-wave discharges. Another explanation for the effects of cocaine on spike-wave activity em- phasizes cocaine's activity as a dopaminergic agonist. Cocaine is a potent inhibitor of dopamine reuptake [15]; it binds to the dopamine transporter and potentiates dopaminergic neurotransmission [19]. It is well known that dopaminergic antagonists increase the number of spike-wave discharges [45], and it seems logical that the dopaminergic agonist cocaine decreases spikewave activity, although cocaine's effects on serotonergic and noradrenergic systems cannot be excluded.

Intact females were more active than intact males after saline injection in the home cage. This is in agreement with a large amount of literature in which open-field ambulation and wheel running was measured [40] and in which an activating effect of estradiol was found [4].

Acute cocaine administration induced several behavioural changes, in agreement with results reported by others [30]. All animals became more active, but the type and nature of the behavior was dramatically changed as exploratory activity and automatic and passive behavior were reduced and stereotypic head movements (swaying), chaotic head movements, and uncontrolled ambulation were increased. Also after amphetamine, another central stimulant, stereotype head movements are dose-dependently increased and concomitant automatic behaviour, mainly grooming is decreased [33]. The type of the behavioural changes seemed to be qualitatively and quantitatively different for the four groups. Cocaine increased milder forms of stereotypical behaviour such as immobility with head swaying in intact males, but the more severe forms of stereotypical behaviour were predominant in the other three groups of subjects. This was also at least partly reflected in more uncoordinated head movements in females than in males. Others have described that females show larger initial effects of cocaine than males (Glick and Hinds, 1984). From these our present data it can be inferred that testosterone reduces the behavioural effects of a single dose of cocaine.

In an earlier study, van Haaren and Meyer [39] noticed that intact females were more sensitive than ovariectomized females and intact and castrated males to acute cocaine administration when they measured distance travelled. The present results only partially confirm this observation but suggest, in addition, that testosterone may play a role in the acute behavioural effects of cocaine. The lack of clear behavioural differences between intact and ovariectomized female rats found in the present study corresponds well with the data from Peris et al. [30]. These authors did not find an effect of female sex hormones on behaviour after a single injection of cocaine.

The behavioural effects of cocaine after chronic administration found in the present experiment differed from those found after acute cocaine administration in at least two ways. First of all, the behavioural effects seemed to be more serious or more intense: All groups tended to exhibit more uncontrolled ambulation, the most intense type of stereotypical behaviour. This observation suggests that chronic cocaine administration leads to behavioural sensitization [30,32]. Others have found similar effects after a similar drug administration design for amphetamine $[33,35]$. Second, the differences between the four groups appeared to be smaller after chronic cocaine administration. This was apparent from the lack of differences among the four groups after $20 \mathrm{mg} / \mathrm{kg}$. Intact males showed uncontrolled head movements and ambulation after the high dose, in contrast to what was seen after the acute dose, and no longer differed from the other three groups. The lack of differences among the four groups after the highest dose of cocaine might also suggest that a ceiling effect emerged after this dose: All animals were engaged to a large extent in the intense stereotypy and displayed uncoordinated ambulation or head movements. This ceiling effect was not present 
after the low dose of cocaine: Females showed the more intense stereotyped behaviour, whereas the males were predominantly engaged in head swaying. The intact males still showed more passive behaviour than the three other groups, suggesting that after intermittent chronic cocaine administration testosterone still reduces the behavioural effects of cocaine.

The design also allowed us to answer questions about whether the rate of sensitization differed for the four groups. Only the intact males were clearly different in that respect, as head swaying was decreased and uncoordinated head movements and uncoordinated ambulation were increased after chronic compared with acute cocaine administration. These data suggest that intact and ovariectomized female rats sensitize in a comparable way, but that intact males sensitize faster than castrated males and intact and overiectomized females. The first part of this conclusion is in agreement with Robinson and Becker [33] for behavioural sensitization induced by amphetamine; the second part is opposite to theirs. However, two remarks are imperative. First, the sensitization parameter, the amount of change, is partly dependent on the score after acute administration. This did not allow a clear conclusion as to whether the intact males differ from the three other groups, or whether sensitization develops differently. Second, it also seems that the development of sensitization depends on the choice of dependent variable and properties of the testing environment, travel distance in an ambulation box compared with six behavioural categories measured in the home cage $[39,49]$.

Plasma concentrations of both cocaine and benzoylecgonine were found to be dependent on the dose. A decrease in cocaine and an increase in benzoylecgonine plasma concentration over time was found after the low and high dose of cocaine for intact males. The castrated males also showed a decrease in cocaine plasma concentration after the low dose. The other groups showed a steady-state concentration of cocaine and benzoylecgonine, and all groups showed an increase in benzoylecgonine after the high dose of cocaine. Despite some of these differences in within-group comparisons, generally few differences between the four groups were found, suggesting that there were no important differences among the four groups. It must be admitted that this way of drug administration (IP and cumulative dose) does not allow adequate modelling of the pharmacokinetic parameters; in particular, the concentrations after the $20 \mathrm{mg} / \mathrm{kg}$ are difficult to interpret. Moreover, only cocaine's major metabolite was measured, not all metabolites.

However, the higher AUC after the low dose for the males suggests that there are some pharmacokinetic differences among the four groups after chronic administration of cocaine, and we suggest that the clearance might be smaller for males than for females. Also, gonadectomy might have a reducing effect on clearance, as the gonadectomized animals had a larger AUC and a correspondingly higher concentration than the intact groups, but this effect was only found after the second injection. It is not clear whether this latter effect might also be present when independent groups had been used for establishing pharmacokinetic differences among the four conditions. The pharmacokinetic data were intended to be correlated to behavioural and EEG parameters; although differences in kinetics were suggested by our data, the behavioural differences (e.g., more passive behaviour for intact males only) could not be related to plasma levels, because only a gender effect and no interaction was found for pharmacokinetic variables. The EEG data did not reveal differences after chronic administration. Therefore, the pharmacokinetic differences found among the four groups could not be related to the behavioural and EEG data. Moreover, the dynamic effects are the result of the actions of cocaine and its active metabolite. To correlate pharmacodynamic effects with each of the metabolites, they all must be administered as the parent drug.

It can be concluded that endogenous gonadal hormones influence spike-wave activity differentially in male and female rats, and that cocaine administration inhibits spike-wave activity but less in intact males than in castrated males, suggesting that testosterone inhibits the EEG effects of cocaine. Testosteron also inhibits cocaine-induced behavioural effects, and head swaying, chaotic head movements, and uncoordinated ambulation were sensitive parameters. Furthermore, behavioural sensitization occurs after chronic intermittent cocaine administration. Behavioural sensitization seemed to be facilitated by testosterone, but this can be questioned, as there were also acute behavioural differences. Although gender differences in plasma concentrations of cocaine and benzoylecgonine were found, they could not be attributed to the behavioural or EEG effects of cocaine. The study of factors that determine individual differences in drug-induced behaviour might be of value in the future.

\section{ACKNOWLEDGEMENTS}

This research was supported by a grant from the North Atlantic Treaty Organisation (NATO CRG 910547) to GVL and FVH, and a grant from the National Institute on Drug Abuse (DA-06463) to FVH. Wilma Jansen and Francien van der Pol collected the data. Yvonne van Veghel and Maud Eijkenboom assisted in the analyses of the data, and Aart Lagerwerf performed the chromatography.

\section{REFERENCES}

1. Ates, N.; van Luijtelaar, E. L. J. M.; Drinkenburg W. H. I. M.; Coenen, A. M. L. Effects of loreclezole on epileptic activity and on EEG and behaviour in rats with absence seizures. Epilepsy Res. $13: 43-48 ; 1992$

2. Bächström, T.; Epileptic seizures in woman related to plasma estrogene and progesterone during the menstrual cycle. Acta Neurol. Scand. 54:321-347; 1976.

3. Buzsáki G.; The thalamic clock: Emergent network properties, Neuroscience 41:351-364; 1991.

4. Chiodo, L. A.; Caggiula, A. R.; Saller, C. F. Estrogen potentiates the stereotypy induced by dopamine agonists in the rat. Life Sci. $28: 827-835 ; 1981$.

5. Coenen, A. M. L.; Drinkenburg, W. H. I. M.; Inoue, M.; van Luijtelaar, E. L. J. M. Genetic models of absence epilepsy, with emphasis on the WAG/Rij strain of rats. Epilepsy Res. 12:75-86; 1992.

6. Coenen, A. M. L.; Drinkenburg, W. H. I. M.; Peeters, B. W. M. M.; van Luijtelaar, E. L. J. M. Absence epilepsy and the level of vigilance in rats of the WAG/Rij strain. Neurosci. Biobehav. Rev. 15:259-263; 1991.

7. Coenen, A. M. L.; van Luijtelaar, E. L. J. M. The WAG/Rij model for absence epilepsy: Age and sex factors. Epilepsy Res. 1:297-301; 1987.

8. Coenen, A. M. L.; van Luijtelaar, E. L. J. M. Effects of diazepam and two beta-carbolines on epileptic activity and on EEG and behavior in rats with absence seizures. Pharmacol. Biochem. Behav. $31: 1-9 ; 1989$.

9. Costa, P. J.; Bonnycastle, D. D. Effect of DCA, compound E, testosterone, progesterone and ACTH in modifying "agene induced" convulsions in dogs. Arch. Int. Pharmacodyn. Ther. 91:330-338; 1952.

10. Cramer, J. A.; Jones, E. E. Reproductive function in epilepsy, Epilepsia 32:S19-S26; 1991.

11. Dalby, M. A.; Epilepsy and 3 per second spike and wave rhythms. A clinical, electroencephalographic and prognostic analysis of 346 patients. Acta Neurol. Scand. 45:S40; 1969.

12. Dirksen, R.; Lerou, J.; Lagerwerf, A.; Vree, T.; Nijhuis, G. M.; Gielen, M.; Booij, L. H. D. J.; Jurna, I. A small animal model for phar- 
macological studies of general anesthetic agents. Eur. J. Anesthesiol. 7:285-298; 1990 .

13. Drinkenburg, W. H. I. M; Coenen, A. M. L.: Vossen, J. M. H.; van Luijtelaar, E. L. J. M. Spike-wave discharges and sleep-wake states in rats with absence epilepsy, Epilepsy Res. 9:218-224; 1991.

14. Glick, S. D.; Hinds, P. A. Sex differences in sensitization to cocaine induced rotation. Eur. J. Pharmacol. 30:67-70, 1986

15. Greer, C. A.; Alpern, H. P. Maturational changes related to dopamine in the effects of d-amphetamine, cocaine, nicotine, and strychnine on seizure susceptibility. Psychopharmacology 64:255-260: 1979.

16. Harris, J. E.; Baldessarini, R. J. Uptake of [ $\left.{ }^{3} \mathrm{H}\right]$-catecholamines by homogenates of rat corpus striatum and cerebral cortex: Effects of amphetamine analogues. Neuropharmacol. 12:669-679; 1973.

17. Karler, R.; Petty, C.; Calder, L.; Turkanis, S. A. Proconvulsant and anticonvulsant effects in mice of acute and chronic treatment with cocaine. Neuropharmacology 28:709-714; 1989.

18. Kokka, N.; Sapp, D. W.; Witte, U.; Olsen, R. W. Sex differences in sensitivity to pentylenetetrazol but not GABAa receptor binding. Pharmacol. Biochem. Behav. 43:441-447; 1992.

19. Konkol, R. J.; Erickson, B. A.; Doerr, J. K.; Hoffman, R. G.; Madden, J. A. Seizures induced by the cocaine metabolite benzoylecgonine in rats. Epilepsia 33:420-427; 1992.

20. Kuhar, M. J.; Ritz, M. C.; Boja, J. W. The dopamine hypothesis of the reinforcing properties of cocaine. Trends Neurosci. 14:299-302; 1991.

21. Lampert, B. M.; Stewart, J. T. Determination of cocaine and selected metabolites in canine and human serum by reversed-phase HPLC on coupled cyanopropyl and silica columns. J. Chromatogr. 495:153$165 ; 1989$

22. Lau, C. E.; Ma, F.; Falk, J. L. Simultaneous determination of cocaine and its metabolites with caffeine in rat serum microsamples by highperformance liquid chromatography. J. Chromatogr. 532:95-103; 1990.

23. Maggi, A.; Perez, J. Role of female gonadal hormones in the CNS: Clinical and experimental aspects. Life Sci. 37:893-906; 1985.

24. Marley, R. J.; Goldberg S. R. Pharmacogenetic assessment of the effects of carbamazepine on cocaine-kindled and cocaine-induced seizures. Brain Res. 579:43-49; 1992.

25. Mattson, R. H.; Kramer, J. A.; Caldwell, B. V.; Cramer, J. A. Seizure frequency and the menstrual cycle: A clinical study. Epilepsia $22: 242 ; 1981$

26. Mishra, P. K.; Dailey, J. W.; Reigel, C. E.; Jobe; P. C. Brain norepinephrine and convulsions in the genetically epilepsy-prone rat: Sex dependent responses to RO 4-1284 treatment. Life Sci. 42:1131-1137; 1988

27. Newmark, M. E.; Penry, J. K. Catamenial epilepsy: A review. Epilepsia $21: 281-300 ; 1980$

28. Noldus, L. P. J. J. The observer: A software system for collection and analysis of observational data. Behav. Res. Meth. Instrum. Comp. 23:415-429; 1991.

29. Peeters, B. W. M. M.; Kerbusch, J. M. L.; Coenen, A. M. L.; Vossen, J. M. H.; van Luijtelaar, E. L. J. M. Genetics of spike-wave discharges in the electroencephalogram (EEG) of the WAG/Rij inbred strain: A classical mendelian crossbreeding study. Behav. Genet. 22:361-368; 1992.

30. Peeters, B. W. M. M.; Spooren, W. P. J. M.; van Luijtelaar, E. L. J. M.; Coenen, A. M. L. The WAG/Rij model for absence epilepsy: Anticonvulsant drug evaluation. Neurosci. Res. Commun. 2:93-97; 1988.

31. Peris, J.; Decambre, N.; Coleman-Hardee, M. L.; Simpkins, J. W. Estradiol enhances behavioral sensitization to cocaine and amphet- amine-stimulated striatal [ $\left.{ }^{3} \mathrm{H}\right]$ dopamine binding. Brain Res. 566:255-264; 1991

32. Pfaff, D. W.; McEwen B. S. Actions of estrogens and progestins on nerve cells, Science 219:808-814; 1983.

33. Post, R. M.; Contel, N. R. Human and animal studies of cocaine: Implications for development of behavioral pathology. In: Creese I., ed. Stimulants: Neurochemical, behavioral and clinical perspective. New York: Raven Press; 1983:163-203.

34. Robinson, T. E.; Becker, J. B. Enduring changes in brain and behavior produced by chronic amphetamine administration: A review and evaluation of animal models of amphetamine psychosis. Brain Res. Rev. 11:157-198; 1986

35. Sato, S.; Dreifuss, F. E.; Penry, J. K.; Kirby, D. D.; Palesch, Y. Longterm follow-up of absence seizures. Neurology 33:1590-1595; 1983.

36. Segal, D. S.; Geyer, M. A.; Schuckit, M. A. Stimulant-induced psy chosis: An evaluation of animal models. In: M. B. H. Youdim; W Lovenberg; Sharman, D. F.; Lagnado, J. R., eds. Essays in neurochemistry and neuropharmacology, vol. 5, London: John Wiley; 1981:95-129.

37. Steriade, M; Llinas, R. R. The functional states of the thalamus and the associated neuronal interplay. Physiol. Rev. 68:649-742; 1988

38. Stripling, J. S.; Russell, R. D. Effects of cocaine and pentylenetetrazol on cortical kindling. Pharmacol. Biochem. Behav, 23:573$581: 1987$

39. Tebbett, I. R.; McCartney, Q. W. A rapid method for the extraction of cocaine and benzoylecgonine from body fluids. Forens. Sci. Int $39: 287-291 ; 1988$

40. van Haaren, F.; Meyer, M. E. Sex differences in locomotor activity after acute and chronic administration. Pharmacol. Biochem. Behav. 39:923-97; 1991 .

41. van Haaren, F.; van Hest, A.; Heinsbroek, R. P. W. Behavioural differences between male and female rats: Effects on gonadal hormones on learning and memory. Neurosci. Biobchav. Rev. 14:2333; 1990.

42. van Luijtelaar, E. L. J. M.; Coenen, A. M. L. Two types of electrocortical paroxysms in an inbred strain of rats. Neurosci. Lett. $70: 393-397 ; 1986$

43. van Luijtelaar, E. L. J. M.; Coenen, A. M. L. Circadian rhythmicity in absence epilepsy in rats. Epilepsy Res. 2:331-336; 1988.

44. van Luijtelaar, E. L. J. M.; de Bruijn, S. F. T. M.; Declerck, A. C.; Renier. W. O.; Vossen J. M. H.; Coenen, A. M. L. Disturbances in time estimation during absence seizures in children. Epilepsy Res. 9:148-153; 1991 .

45. van Luijtelaar, E. L. J. M.; van der Werf, S. J.ssen, J. M. H.; Coenen, A. M. L. Arousal, performance and absence seizures in rats. Electroenceph. Clin. Neurophysiol. 79:430-434; 1991.

46. Warter, J. M.; Vergnes, M.; Depaulis, A.; Tranchant, C.; Rumbach, L.: Micheletti, G.; Marescaux, C. Effects of drugs affecting dopaminergic neurotransmission in rats with spontaneous petit-mal-like seizures. Neuropharmacology $2: 269-274 ; 1988$

47. Werboff J.: Hedlund, L.; Havlena, J. Audiogenic seizures in adul castrated rats treated with various hormones. Endocrinology 3:389397; 1963.

48. Wilson, M. A. Influences of gender, gonadectomy, and estrous cycle on $\mathrm{GABA} / \mathrm{BZ}$ receptors and benzodiazepine responses in rats. Brain Res. Bull. 29:165-172; 1992 .

49. Wooley, D. E.; Timiras, P. S. The gonad-brain relationship: Effects of female sex hormones on electroshock convulsion in the rat. Endocrinology 70:196-209; 1962.

50. Woolverton, W. L.; Johnson, K. M. Neurobiology of cocaine abuse, Trends Pharmacol. Sci. 13:193-200; 1992. 